\title{
Simulation of large-scale thermal storage in fragmented rock modelled as a discretised porous medium - application to the Natural Heat Exchange Area at Creighton Mine
}

\author{
N Saeidi MIRARCO Mining Innovation, Canada \\ A Romero Université libre de Bruxelles, Belgium \\ L Fava MIRARCO Mining Innovation, Canada \\ C Allen Vale Canada Limited, Canada
}

\begin{abstract}
The Natural Heat Exchange Area (NHEA) is a large-scale fractured rock mass at Creighton Mine, created by previous sublevel cave mining, that is used to seasonally store thermal energy with the purpose of moderating the temperature of ventilating air for the underground mine. The use of the NHEA has avoided the mechanical cooling and heating otherwise required due to the seasonal variations in ambient temperatures. The NHEA has 96 doors through which air enters the mine airways through the mass of broken rock; these doors are manually operated to improve the tempering capacity. The empirical strategy for operating the doors has proven successful so far, but additional cooling is needed as mining progresses deeper.
\end{abstract}

This paper describes two models, a three-dimensional computational fluid dynamics (CFD) model and an analytical network model. The models are calibrated to agree with the history of measured temperature, airflow and pressure at the NHEA. The calibrated models will be used together to support the assessment of both operation and systems design variations.

Keywords: mine ventilation, seasonal heat storage, Natural Heat Exchange Area (NHEA), porous medium, computational fluid dynamics (CFD) simulation

\section{Introduction}

The Natural Heat Exchange Area (NHEA) system at Vale's Creighton Mine provides natural heating and cooling for the primary intake of the mine's ventilation system. The surface ambient air is continuously drawn from the surface and through a mass of broken rock created during prior sublevel caving operations using three main fans underground. The mass of broken rock allows for storing ambient heat and 'coolth' to condition the ventilating air. During winter, cold temperatures propagate from surface through the broken rock mass as a result of heat transfer between the incoming air and the broken rock. A similar process occurs in summer with a propagation of warm temperatures through the cooler broken rock mass. In other words, the NHEA is acting as a refrigeration system in summer, and a heating system in winter.

The airflow passes through boxholes and slusher trenches to millholes and ore passes. The airflow is controlled using 96 manually operated control doors near the millholes at each trench. The trenches with control doors are divided into four groups known as Blocks 1, 2, 5 and 6 . The slusher trenches of Blocks 3 and 4 are inaccessible. The airflow from different trenches and different blocks is collected at a gathering area known as the 800 Level and from there the ventilating air is directed to the fresh air systems of the mine. The 3D geometry of the system is presented in Figure 1.

There are sensors installed near the control doors to monitor the air temperature; this sensor data is archived by a real-time data historian - a system that logs time-stamped data. The air temperature at a trench control door changes gradually while the door state is unchanged. Once the temperature at a given 
door surpasses a pre-established trigger value, the door state will be manually changed. The trigger value, arrived at empirically, is a function of depth, block and season. Following this strategy, the NHEA has been an efficient replacement of mechanical heating and cooling systems for decades. However, estimates show that the current methods of operating the NHEA system will not provide sufficient cooling as the mine develops deeper (Ramsden et al. 2014).

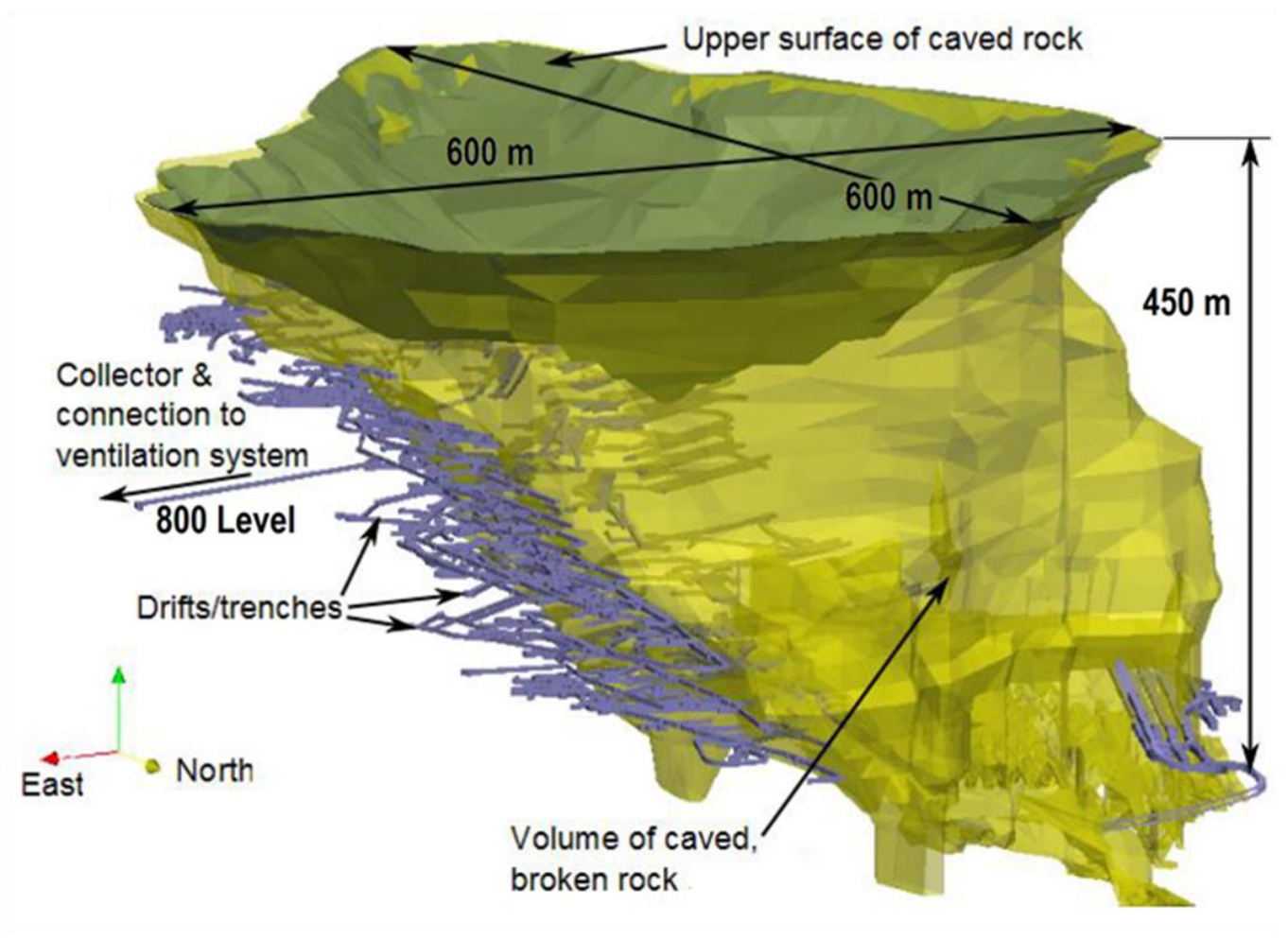

Figure 1 3D geometry of the NHEA and its surrounding mining structures (Schafrik 2014)

The present work aims to identify and assess engineering options for increasing the cooling capacity of the NHEA, to avoid or delay the need for mechanical refrigeration while providing effective ventilation for Creighton Mine throughout the year. For the purpose of enhancing knowledge about the current NHEA system and identifying potential engineering options, a three-dimensional computational fluid dynamics (CFD) model and an analytical 'network model' of the system has been built. Models are calibrated using archived sensor data and can be used for primary guidance for potential engineering designs to improve the NHEA system. In this paper, both models are introduced in detail and the simulation results are discussed for potential improvements to the system.

\section{The three-dimensional computational fluid dynamics model}

The CFD modelling of the NHEA system focuses on simulation of the thermodynamic interactions between the air and broken rock to compute the air temperature at each of the 96 control doors throughout the year. In this section, the NHEA's CFD model is described and the results of the simulation are discussed.

\subsection{Geometry and boundary conditions}

Using ANSYS 17.1 - DesignModeler (ANSYS, Inc. 2017), the geometry of the NHEA and size and location of the 96 control doors are modelled with reference to the geometry presented in Figure 1 . The meshed geometry of the NHEA is presented in Figure 2 where groups of control doors (blocks) are discretised with higher mesh element density. The mesh properties and model dimensions are reported in Table 1. 


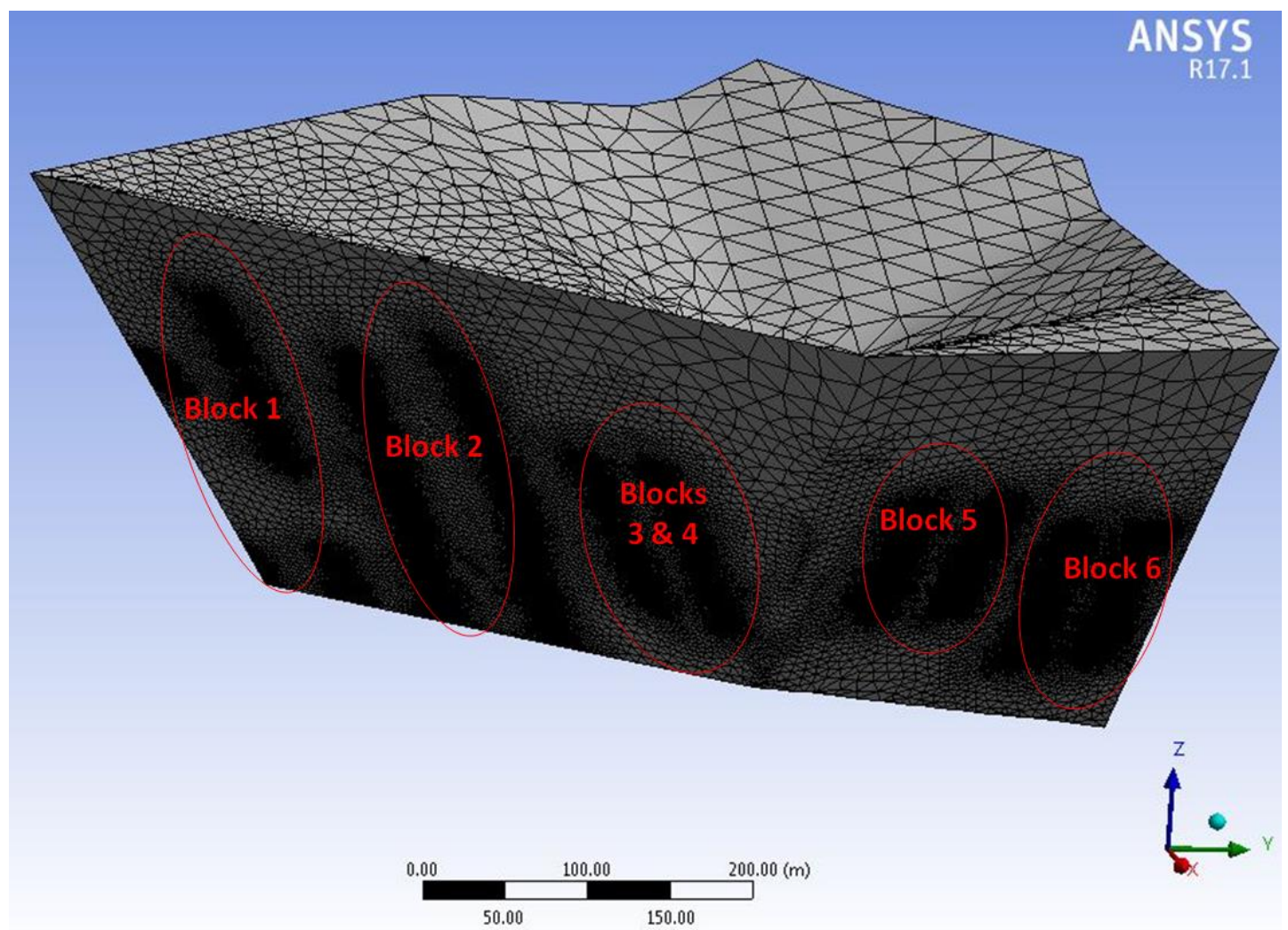

Figure 2 The NHEA and control doors built with ANSYS 17.1 - DesignModeler, with each group of control doors highlighted with red circles and the block numbers labelled

Table 1 Mesh properties and dimensions of the NHEA's CFD model designed with ANSYS 17.1 - DesignModeler

\begin{tabular}{cccc}
\hline Number of mesh elements & Type of mesh elements & Geometry volume & Top surface area \\
\hline $1,831,416$ & Tetrahedron & $49,000,000 \mathrm{~m}^{3}$ & $336,000 \mathrm{~m}^{2}$ \\
\hline
\end{tabular}

The transient heat transfer between the ambient air and the mass of broken rock is modelled with local thermal equilibrium and transient boundary conditions considering a period of 10 years. The data used are recorded from January 2008 to December 2015. The first two years are repeated twice to fulfil a period of 10 years, the minimum length of simulation required for CFD model calibration. The inlet boundary condition applied to the top surface of the NHEA is defined with inlet velocity at a constant airflow of $0.0024 \mathrm{~m} / \mathrm{s}$ (approximately $800 \mathrm{~m}^{3} / \mathrm{s}$ ) and a transient daily average ambient temperature reported by Environment Canada (Environment and Climate Change Canada 2017). The transient temperature was set with User-Defined Function (UDF) (ANSYS, Inc. 2017) written in the C language. The outlet boundary conditions that applied to each of the 96 control doors are defined with outflow boundary condition in ANSYS - Fluent (ANSYS, Inc. 2017) which weights the flow velocity exiting from each of the trench doors. Based on the daily door states that have been archived by Creighton Mine's ventilation crew, an outflow value of zero is assigned if the control door is closed and one if the control door is open, utilising a journal file. The defined boundary conditions are affected by the availability and accuracy of the historical data recorded at the NHEA.

The volume of the broken rock in the NHEA is defined as a porous zone and the value of its porosity is calculated from the estimated bulking factor of 25 to $30 \%$ from the previous mining activities at the site (Schafrik 2014). The porous zone is assumed to be initially homogenous, which might be a subject of change in further development of the CFD model. The value of porous zone permeability is defined based on the measured values of airflow and pressure at different locations within the NHEA. The defined values for thermo-physical properties of the NHEA's CFD model are reported in Table 2. 
Table 2 Thermo-physical properties of the NHEA's CFD model

\begin{tabular}{cccccccc}
\hline $\begin{array}{c}\text { Rock } \\
\text { thermal } \\
\text { conductivity }\end{array}$ & $\begin{array}{c}\text { Rock } \\
\text { specific heat } \\
\text { capacity }\end{array}$ & $\begin{array}{c}\text { Rock } \\
\text { density }\end{array}$ & $\begin{array}{c}\text { Permeability } \\
\text { of porous } \\
\text { zone }\end{array}$ & Porosity & $\begin{array}{c}\text { Air thermal } \\
\text { conductivity }\end{array}$ & $\begin{array}{c}\text { Air specific } \\
\text { heat } \\
\text { capacity }\end{array}$ & $\begin{array}{c}\text { Air } \\
\text { density }\end{array}$ \\
\hline 2 & 800 & 3,000 & 0.0133 & 20 & 0.0242 & 1006.43 & 1.205 \\
$W / \mathrm{m} . \mathrm{K}$ & $\mathrm{J} / \mathrm{kg} \cdot \mathrm{K}$ & $\mathrm{kg} / \mathrm{m}^{3}$ & $\mathrm{~m}^{2}$ & $\%$ & $\mathrm{~W} / \mathrm{m} . \mathrm{K}$ & $\mathrm{J} / \mathrm{kg} . \mathrm{K}$ & $\mathrm{kg} / \mathrm{m}^{3}$ \\
\hline
\end{tabular}

\subsection{Numerical methodology}

The model was solved by ANSYS 17.1 - Fluent (ANSYS, Inc. 2017) using the Semi-Implicit Pressure Linked Equations (SIMPLE) algorithm, second-order upwind discretisation and the algebraic multi-grid (AMG). The simulations ran for a period of 10 years with 3,653 time steps, 20 iterations per time step and an 86,400 second step-size (one day). The 10 year period of the simulation is defined with trial and error to assure that the simulation results are not affected by the arbitrary initialisation of the model. Each simulation took seven days to run on a 64-bit PC running Windows 7, with 32 GB RAM and an Intel ${ }^{\circledR}$ Core $^{\mathrm{TM}}$ i7-4770k CPU @ $3.5 \mathrm{GHz}$ processor.

\subsection{Validation of the simulation results}

The CFD simulation results were validated based on the field-measured temperatures at each of the 96 control doors and the ambient air temperature, for the year 2015. Considering the sinusoidal wave-like behaviour of the temperature curves in a period of one year, temperature curves at each of the control doors can be characterised with a value of phase (shift from the surface ambient air temperature curve) and amplitude (temperature range). Comparison of these two characteristics of the measured and simulated temperature curves at each of the control doors is the rationale to validate the CFD simulation results. It was found that with the defined thermo-physical properties and boundary conditions, the CFD model results were in good agreement with the field measurements. The temperature range at all outlets matched with the temperature range at their corresponding control doors. However, the phase-shifts matched at only $70 \%$ of the control doors. This might be due to inaccurate data for trench door locations, in addition to simplified boundary conditions and porous zone properties. Despite these, the current CFD model is capable of accounting for the fundamental thermodynamic behaviour of the NHEA.

\section{$2.4 \quad$ Results discussion}

The CFD simulation results are presented in Figure 3 . The simulated temperature curves and measured temperature curves at the control doors for three locations of the NHEA (close to the surface, mid-depth and the bottom) are plotted against the ambient temperature curves at the year 2015 (year 10 of the simulation). The simulated temperature at the NHEA model outlets (in black) show an acceptable match with the measured temperature at the corresponding trench doors (in red), both in terms of temperature range and the phase shift from the ambient air temperature on the surface (in blue). The shift between the ambient air temperature graph and the control door temperature graph, as well as the reduction in the temperature range is a confirmation of the heat exchange that occurs between rock and air in the porous zone.

In addition, Figure 3 illustrates the temperature contours distribution in a cross-section of the NHEA and airflow trajectories across the entire NHEA for December 2015. At deeper levels of the NHEA, air has travelled deeper with longer trajectories. As a result, the air temperature has moderated to a relatively constant value (approximately $4^{\circ} \mathrm{C}$ ) year-round at the control doors and within the porous zone. In contrast, closer to the surface, the temperature is more affected by the variation in the ambient air behaviour. This can be a measure for evaluation of engineering options with a calibrated CFD model. 


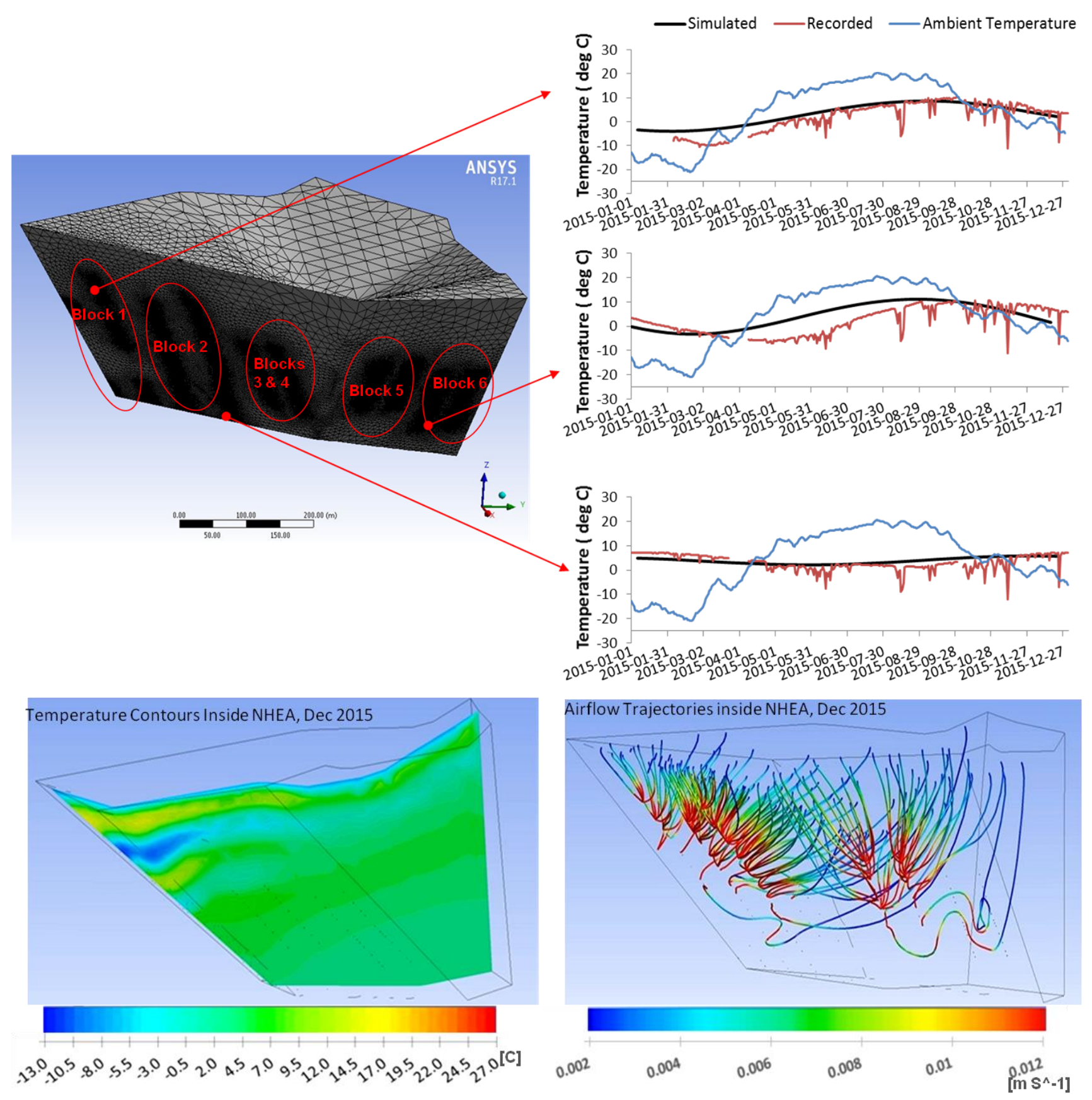

Figure 3 Simulation results and measured data for selections of the NHEA outlets in the final year of simulation (2015) (top), as well as temperature contours in a cross-section of the NHEA and airflow trajectories across the entire area for December 2015 (bottom)

\section{$3 \quad$ Analytical network model}

In this section, the analytical model developed to capture the thermodynamic interactions between the air and the NHEA's mass of broken rock is described and the results of the simulations are discussed. 


\subsection{Network Heat Exchange Model}

The analytical model of the NHEA, referred to as the Network Heat Exchange Model (HEM), was developed using Simulink - MATLAB (The MathWorks, Inc. 2017). This model consists of a ventilation network coupled with mass elements acting as heat storage nodes. A schematic presentation of the Network HEM is presented in Figure 4.

In this model, the NHEA's mass of broken rock is considered to be a porous zone. In order to capture the rock mass geometry, mass and the total heat transfer area, the discretisation of the porous zone is different for each of the NHEA's blocks. All these parameters were subject to a non-exhaustive manipulation based on objective, measurable data defining the NHEA geometry. For example, Blocks 2 and 6 contain a larger portion of the rock mass compared to the other blocks, so they are given a greater share of the total rock mass. Even though the rock mass varies at different blocks, a fairly constant ratio of heat transfer area to block mass has been estimated for all of them which is between $3 \times 10^{-6}$ to $4 \times 10^{-6} \mathrm{~m}^{2} / \mathrm{kg}$. The heat transfer coefficient is assumed to be $90 \mathrm{~W} / \mathrm{m}^{2} \mathrm{~K}$, from which the previous ratio is derived.

Pressure drop and flow across the control doors were compared with analytical expressions (McPherson 1993) yielding results in close agreement. The open or closed door state is presented in terms of door resistance. The simulation model assumes in general a door resistance, when open, of $0.365 \mathrm{Ns}^{2} / \mathrm{m}^{8}$ for large doors $\left(16 \mathrm{ft}^{2}\right)$ and $4 \mathrm{Ns}^{2} / \mathrm{m}^{8}$ for the smaller ones $\left(8 \mathrm{ft}^{2}\right)$. Note that the shock losses increase more than the expected square ratio of the areas because of the effect of the vena contracta and its dependency on the relative size of the orifice to the drift in which it is placed (McPherson 1993). The analytical pressure flow showed good agreement with site measurements at each door.

In order to limit the size of the model, control doors are grouped and assigned to notional superlevels. The equivalent resistance of a superlevel is calculated considering parallel flows, and including an additional airway with an adjustable resistance to account for leakage; that is, airflow that passes through the NHEA without passing through control doors. Flow measurements at the NHEA indicate that 30 to $60 \%$ of the flow through each block does not pass through the control doors. This will be discussed in Section 4. Leakage resistances range from 0.5 to $10 \mathrm{Ns}^{2} / \mathrm{m}^{8}$ if the model is adjusted for each block independently, but in the current model, a typical value of $1 \mathrm{Ns}^{2} / \mathrm{m}^{8}$ was selected for all superlevels in the NHEA, with no significant decrease in the model performance.

\section{Inlet boundary conditions: Ambient pressure and temperature}

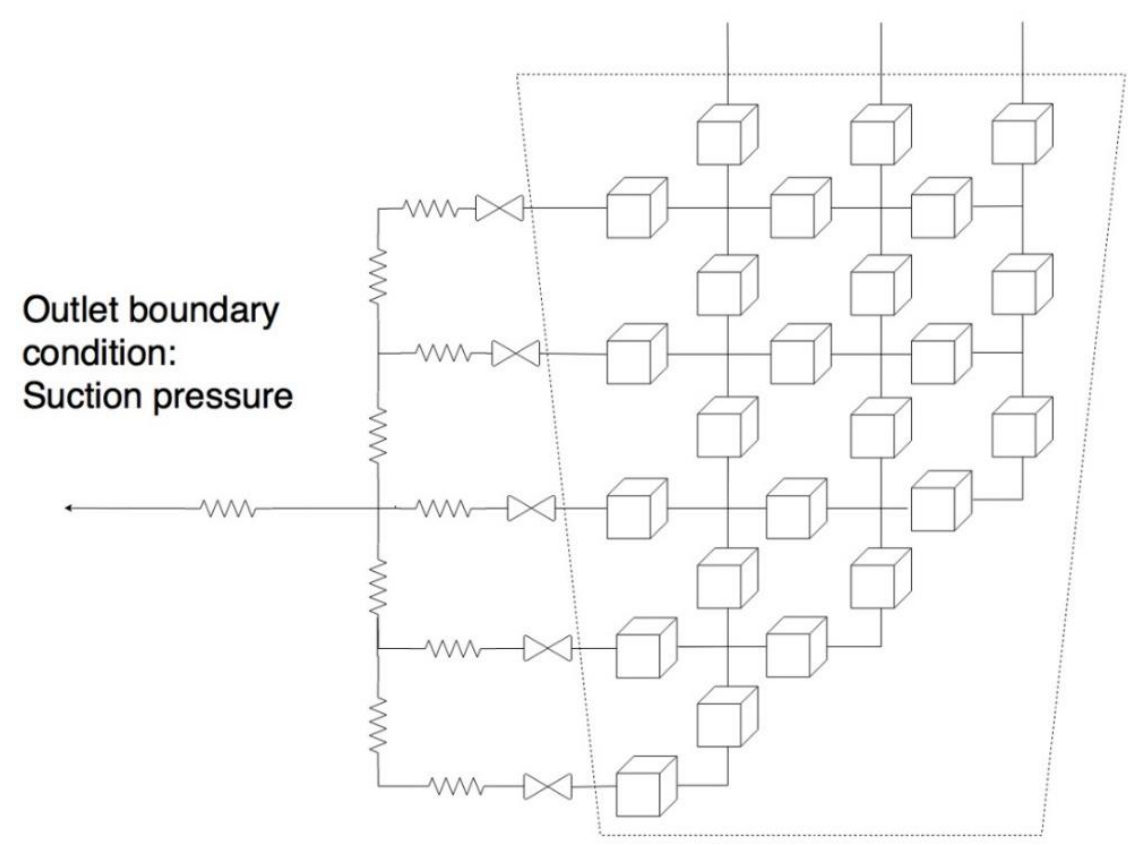

Figure 4 NHEA porous zone discretisation with mass elements and superlevels connected to the collecting area for one block 
The Network HEM for each block of the NHEA combine in a ventilation model to represent the overall NHEA system. The schematic demonstration of this integration is presented in Figure 5.

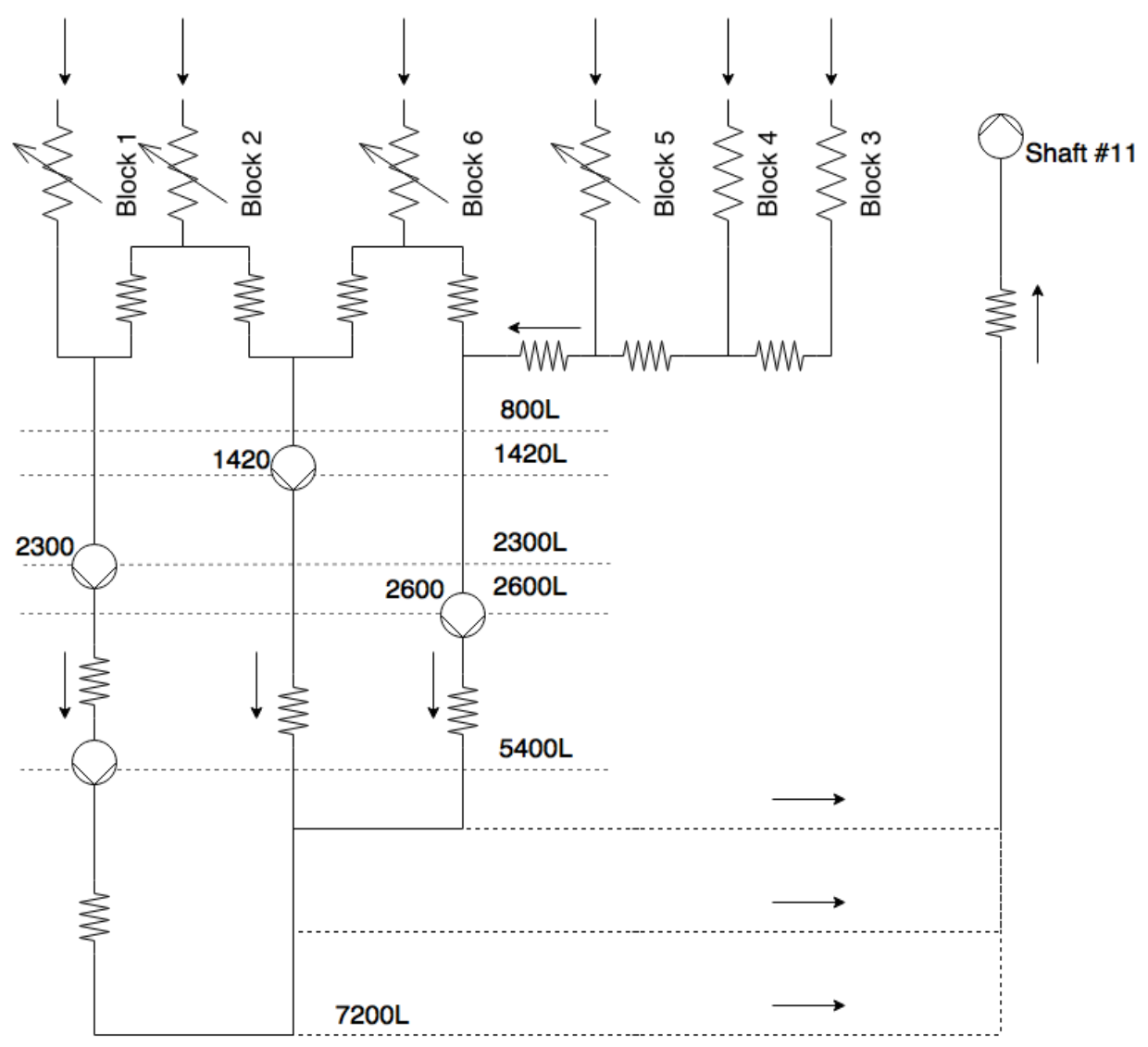

Figure 5 Schematic presentation of Creighton Mine's ventilation system through integration of the Network HEMs for each block. Each of the mine levels is labelled next to the dotted lines. The three sets of main fans are labelled as 1420, 2300 and 2600, which are levels at which the fans are installed. The return air system is named 'Shaft \#11'

The resistance of flow paths in the Creighton Mine ventilation network which are presented with branches in Figure 5 are defined based on the pressure drop and flow measurements in the mine. However, it should be noted that the ventilation network model presented in Figure 5 has been simplified compared to the actual mine's ventilation system. The fan pressures are assumed to remain constant, i.e. the operating point is considered in a somewhat steep area of the fan curve. In Figure 5, the three main sets of fans drawing air through the NHEA are labelled as 1420, 2300 and 2600 and the return air shaft is labelled as 'Shaft \#11'. These simplifications are considered acceptable at this stage of the study since they are not expected to affect the accuracy of the results.

\subsection{Model validation}

This section presents a comparison between the results of the NHEA Network HEM and the historical data from the NHEA. The graphs presented in Figures 6 through 9 show the simulated temperature of the air delivered from Blocks 1, 2, 5 and 6 at the collecting area (800 Level) against the corresponding measured temperature and surface ambient air temperature for a period of five years. There are short periods in the temperature graphs where the simulated and measured temperature do not match, some of which are due to the error of measurement of the temperature sensors located across the collecting area (800 Level) of the NHEA. 


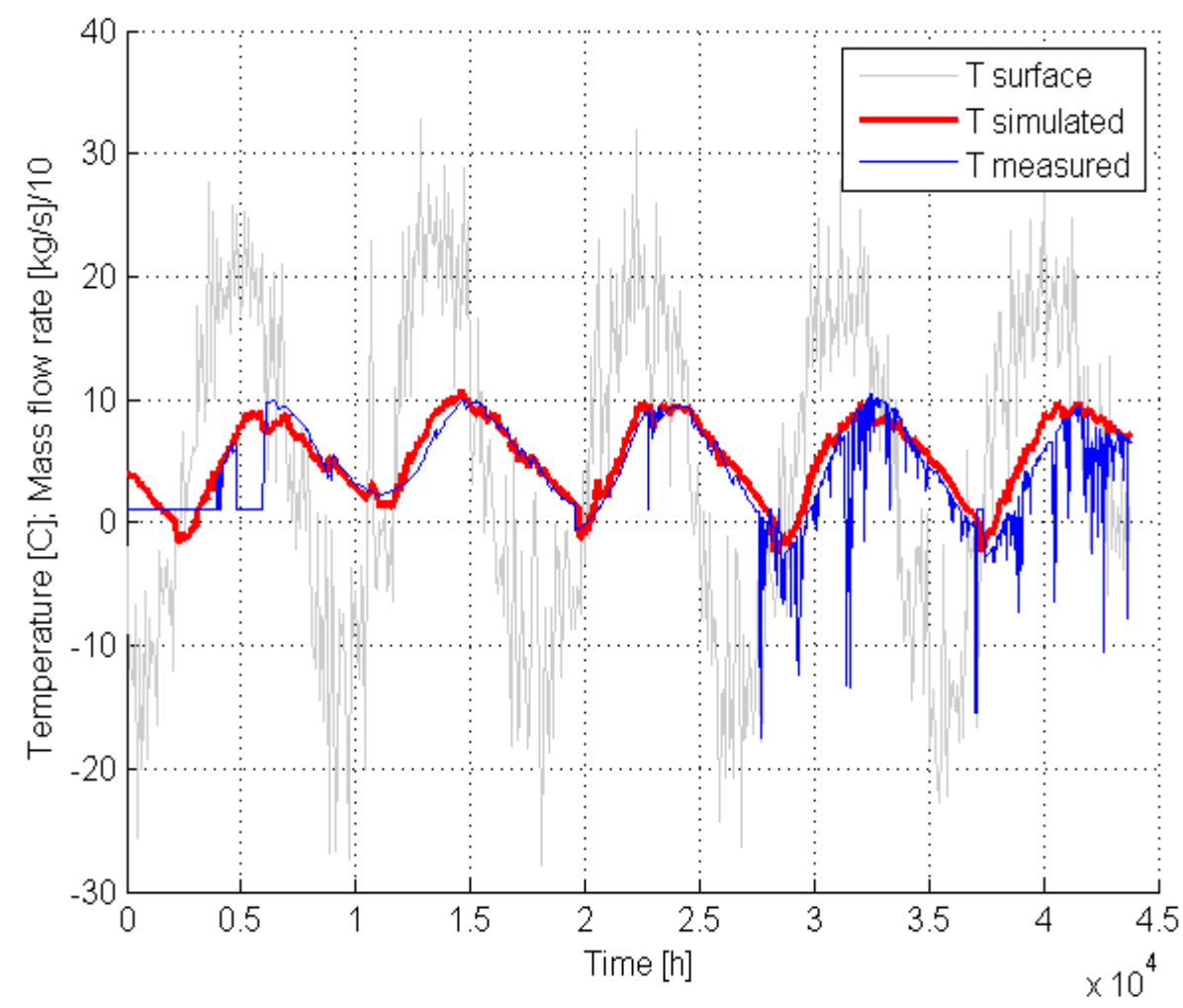

Figure 6 Results of network model validation for Block 1

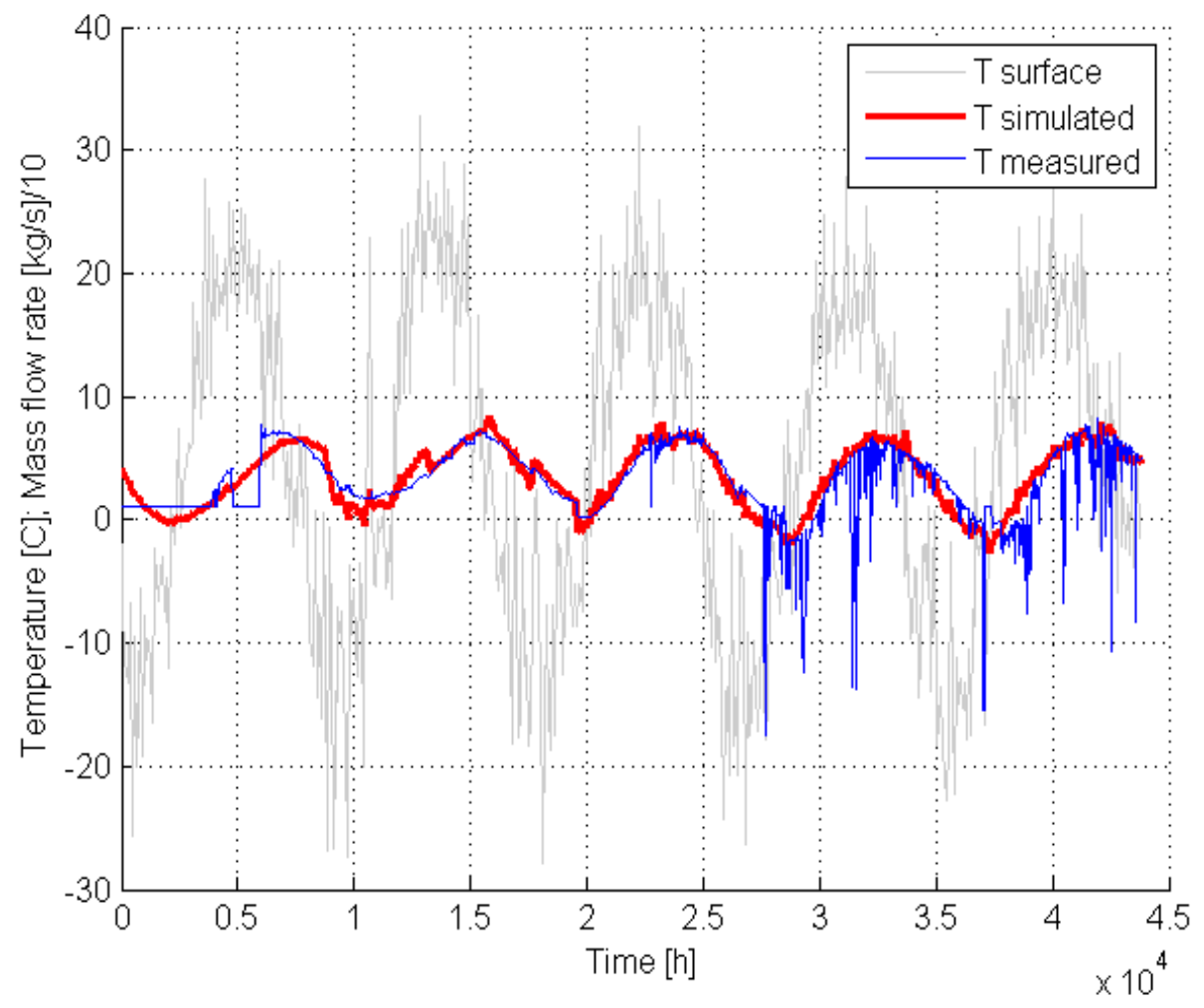

Figure 7 Results of network model validation for Block 2 


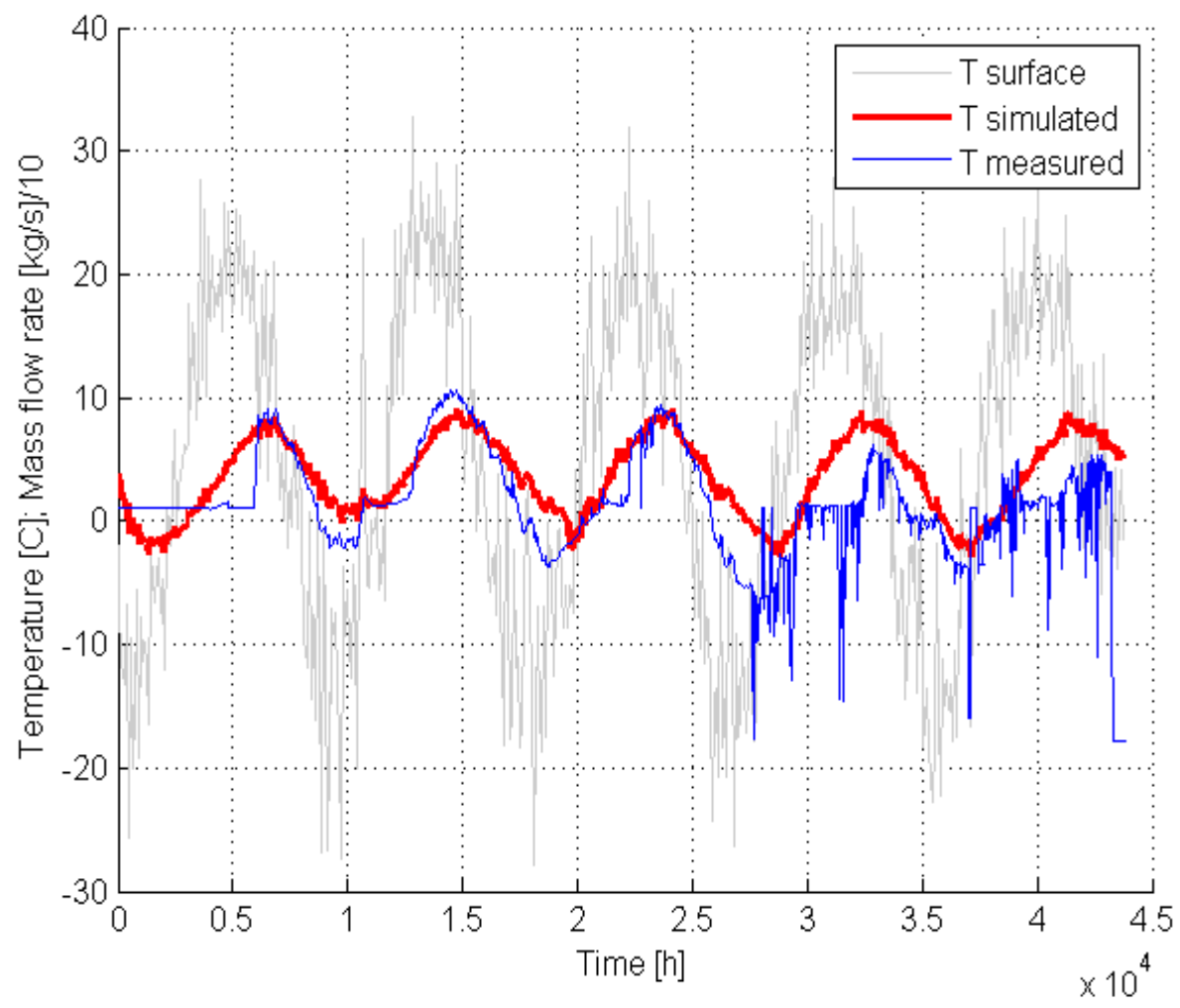

Figure 8 Results of network model validation for Block 5

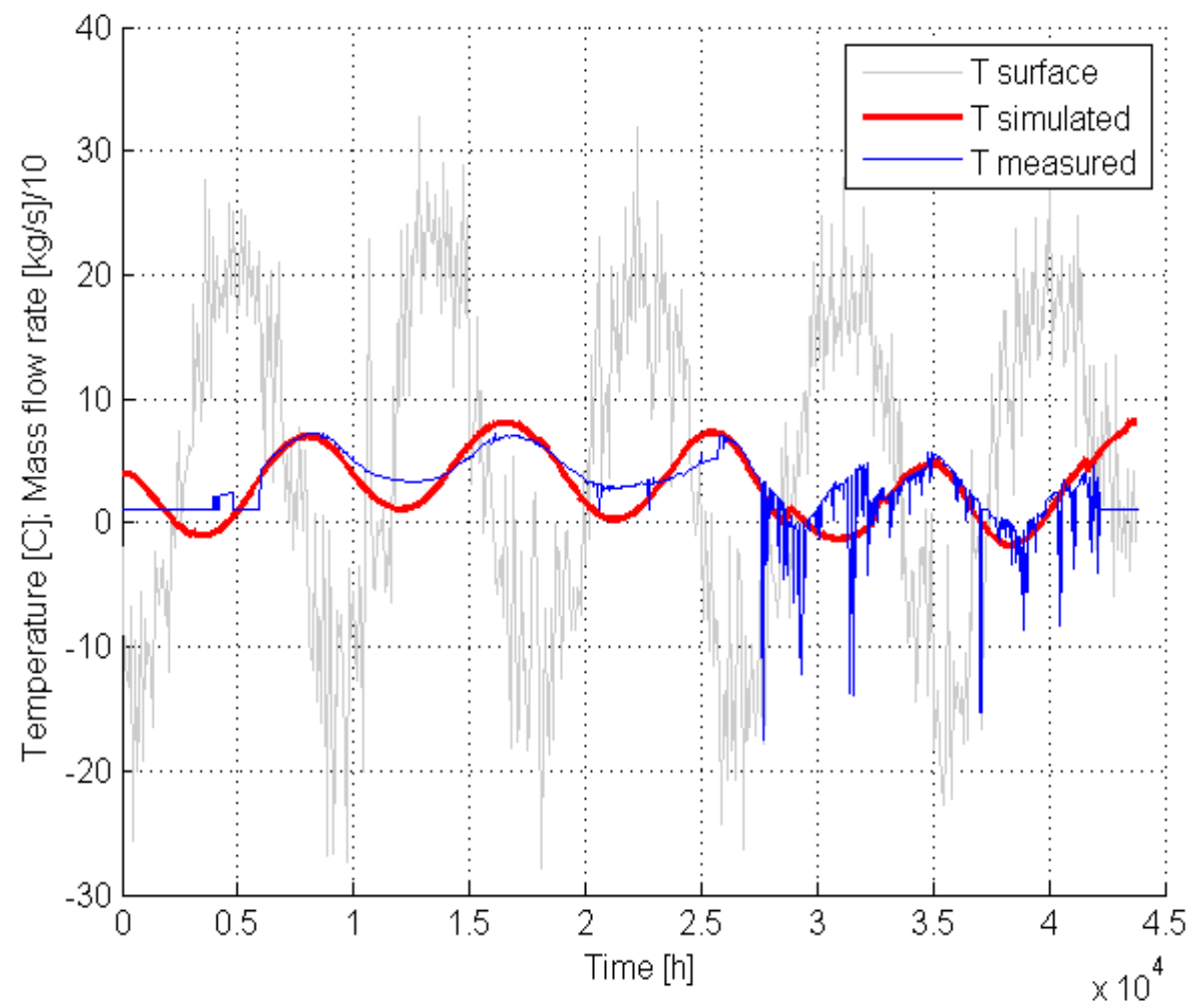

Figure 9 Results of network model validation for Block 6 


\section{Investigations to enhance the NHEA's performance}

In this section, two opportunities that are expected to increase the cooling capacity of the NHEA will be discussed using CFD model and the Network HEM.

\subsection{Using a greater volume of the broken rock mass}

Based on the CFD results presented in Figure 3, showing temperature variation at three different levels of the NHEA as well as the temperature contours at a cross-section of the NHEA, it can be observed that temperature variations at deeper parts of the NHEA are not significant. This can be attributed to having fewer control doors at the bottom of the NHEA which causes less airflow. A study of the old Creighton Mine design maps can guide the selection of potential locations in the bottom of the pit that could connect to the underground ventilation system to pull more air from surface to the bottom of the pit. This could be beneficial to direct cold airflow to the bottom of the system, which will promote the propagation of the mass of cold temperature to deeper parts of the NHEA during the winter. This could potentially cool down a larger volume of the broken rock mass and provide additional cooling capacity during the summer months.

\subsection{Reducing leakage in the system}

The airflow survey conducted at the NHEA control doors and on the collecting area (800 Level) has confirmed that there is a great amount of leakage in the system, an average of 30 to $60 \%$ leakage at each block, which results in uncontrolled air entering the collecting area (800 Level). It is expected that locating and sealing the sources of the leakage will provide the ability to lower the average temperature of the air on the collecting area for delivery to the deeper levels of the mine.

This has been studied using the network model. The current leakage resistances, according to the measured leakage, are presented in Table 3, as well as the resistance values used to simulate an optimistic case in which leaks are reduced as much as possible.

Table 3 Leakage resistance at ramp and at each block within the NHEA that is considered for the network model of the NHEA with current and minimised leakage

\begin{tabular}{l|c|cccc}
\hline & \multicolumn{5}{c}{ Leak resistances $\left(\mathrm{Ns}^{2} / \mathbf{m}^{8}\right)$} \\
& Ramp & Block 1 & Block 2 & Block 5 & Block 6 \\
\hline Current leakage & 10 & 1.0 & 1.0 & 3.0 & 3.0 \\
Minimised leakage & 50 & 50 & 50 & 50 & 50 \\
\hline
\end{tabular}

Figures 10 to 13 present results from the network model of the NHEA for airflow and air temperature delivered from Blocks 1, 2, 5 and 6 for a period of five years (2011 to 2015). Based on the presented results, it can be concluded that, as a result of leakage reduction in the system, the average annual temperature of the air delivered from each block does not change significantly; however, the average peak temperature (maximum temperature) may be reduced by 1.0 to $2.0^{\circ} \mathrm{C}$ in Block 1 and between 0.5 and $2.0^{\circ} \mathrm{C}$ in Blocks 2 , 5 , and 6. Total flow remains mainly unchanged before and after leakage reduction since fans are modelled with constant pressure. This assumption regarding fan operation requires further analysis if leakage reduction is to be pursued. 


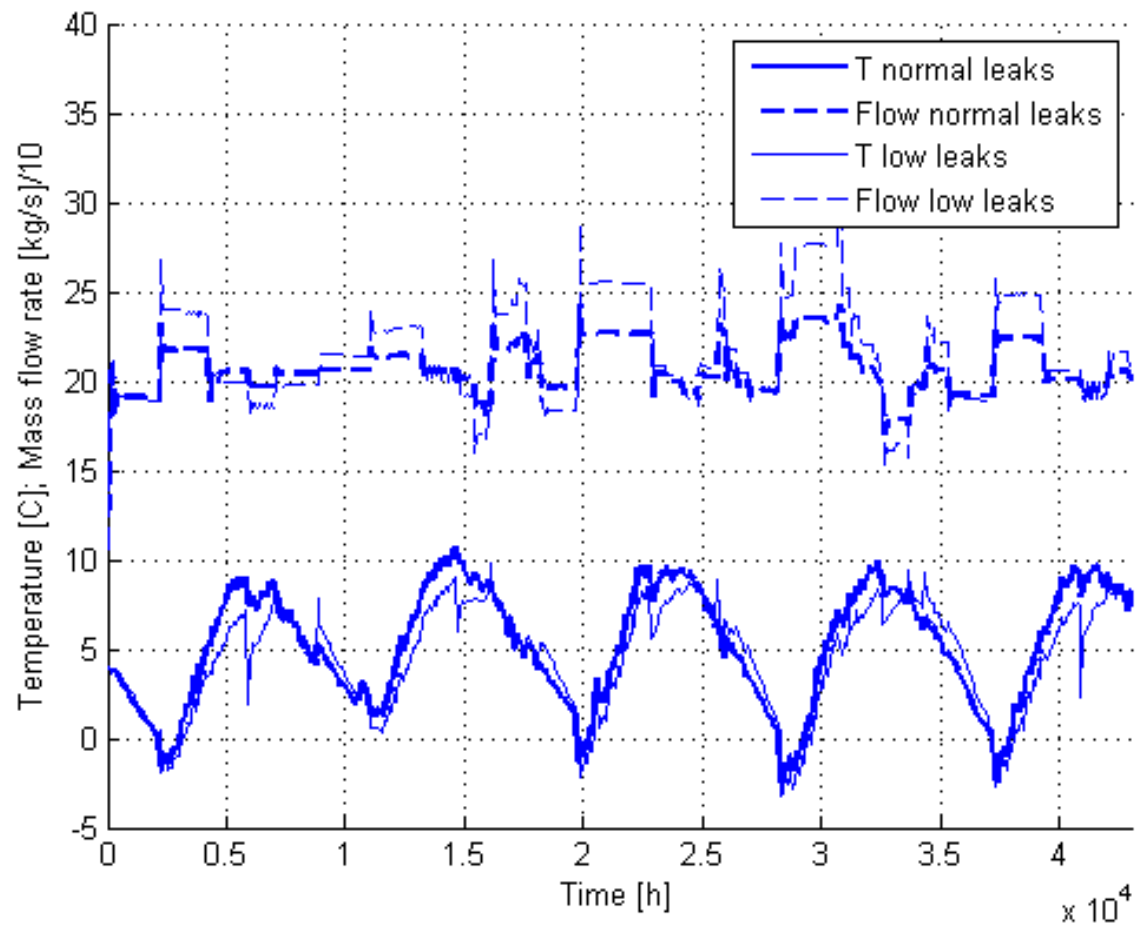

Figure 10 Temperature and airflow delivered from Block 1 considering current leakage (thick solid line) and considering leaks are reduced (dashed lines)

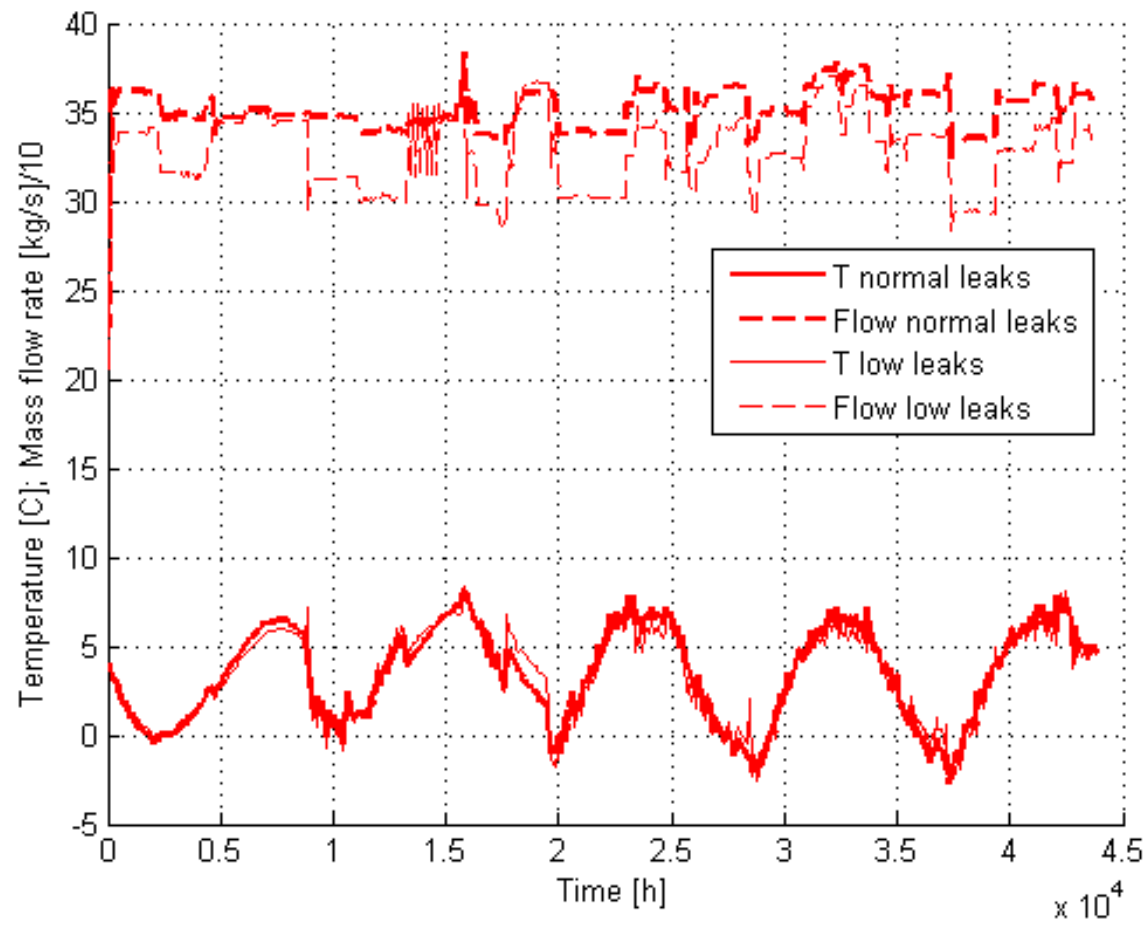

Figure 11 Temperature and airflow delivered from Block 2 considering current leakage (thick solid line) and considering leaks are reduced (dashed lines) 


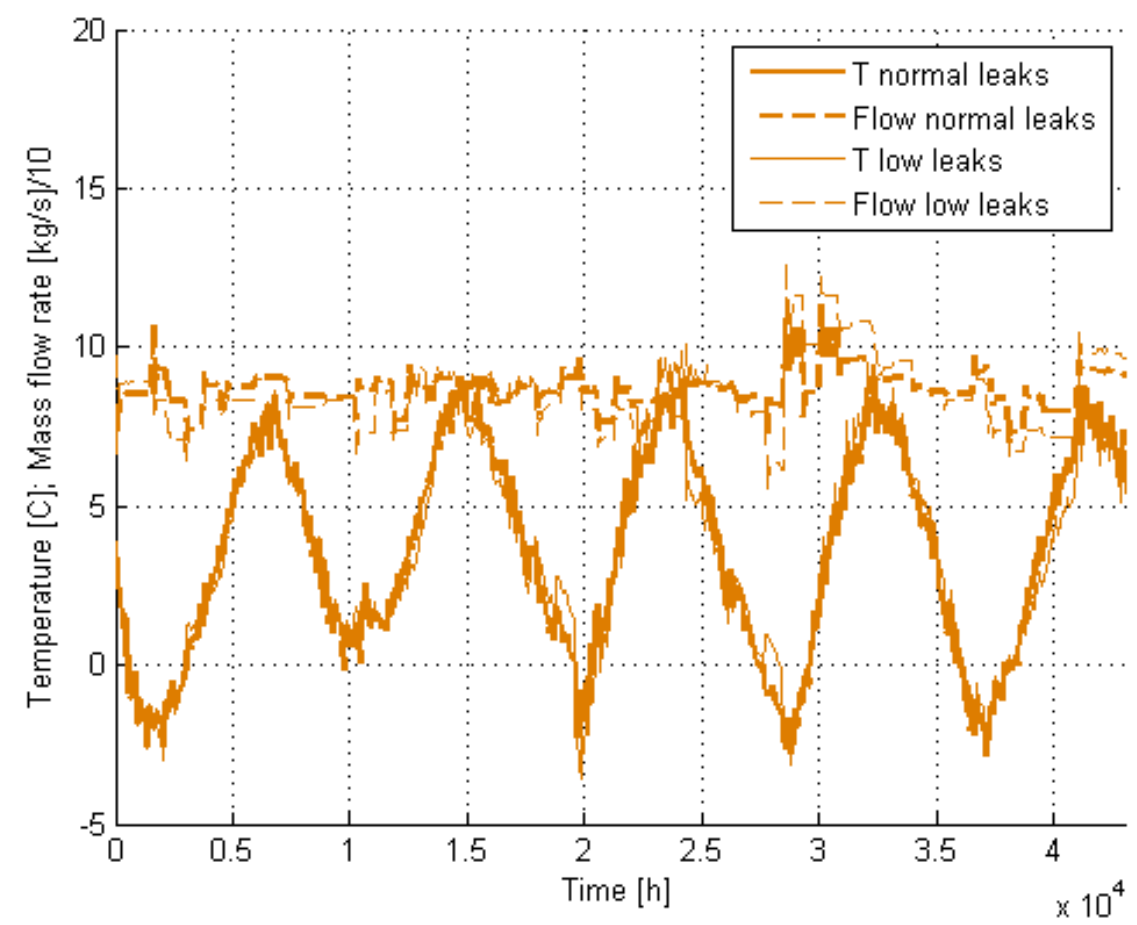

Figure 12 Temperature and airflow delivered from Block 5 considering current leakage (thick solid line) and considering leaks are reduced (dashed lines)

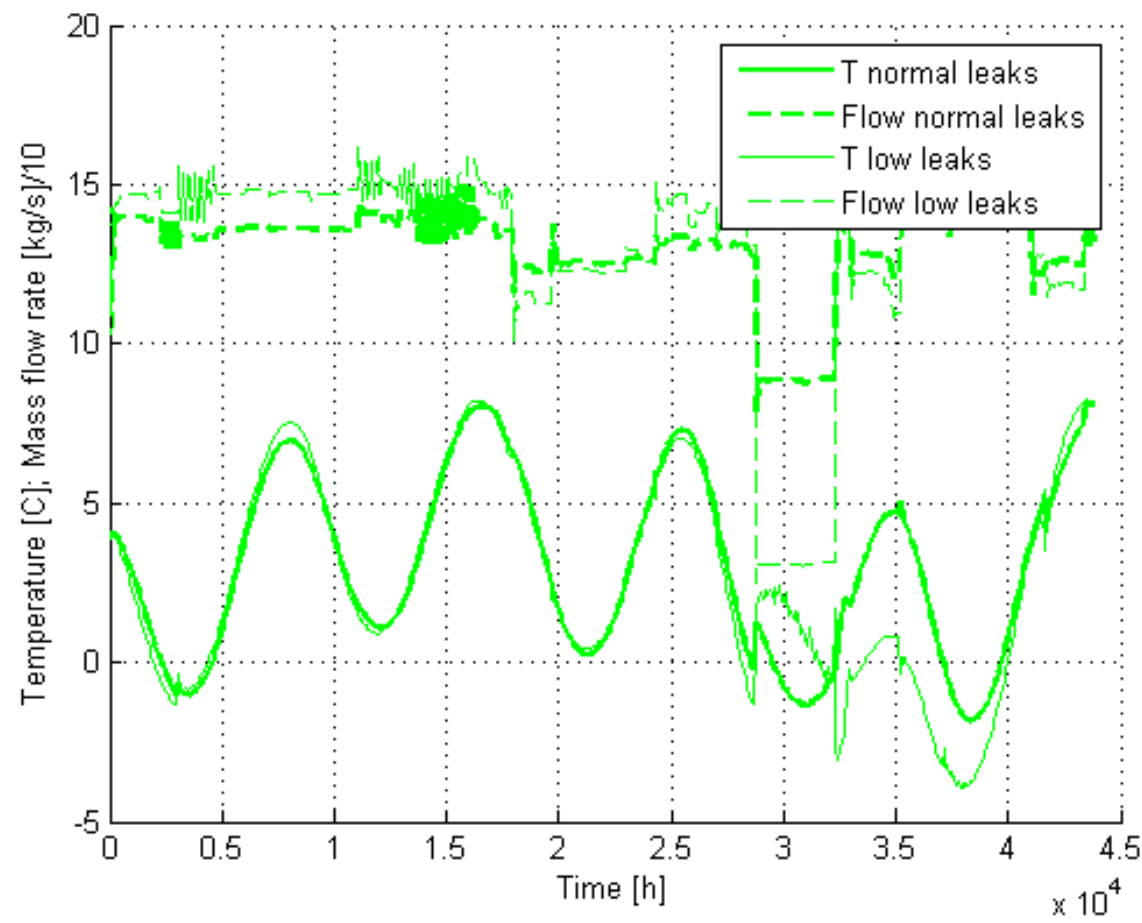

Figure 13 Temperature and airflow delivered from Block 6 considering current leakage (thick solid line) and considering leaks are reduced (dashed lines) 


\section{$5 \quad$ Conclusions and future work}

The NHEA at Vale's Creighton Mine in Sudbury, Ontario, Canada is a valuable asset which provides natural cooling and heating for Creighton Mine's ventilating air. The system is being studied for performance improvements to increase its cooling capacity as deeper levels of the mine come into operation.

A three-dimensional CFD model of the NHEA as well as a network heat exchange model have been designed and calibrated using the recorded temperature data at the NHEA. The models work together to help with identifying and evaluating the opportunities for a different control strategy of the NHEA system to provide cooler ventilating air and to avoid or delay the need for mechanical heating and cooling systems.

The current CFD model is capable of reproducing characteristics of the NHEA qualitatively, which leads to a better understanding of the system. A quantitative calibrated model is essential for the confident evaluation of engineering options to improve NHEA performance and provide cooler air to deeper levels of Creighton Mine. This can be achieved by manipulating the thermo-physical properties of the CFD model and replacing simplified assumptions by more realistic representations. The current calibrated models and historical data recorded at the NHEA can provide the principal guidance for potential modifications to the NHEA system. Two examples of control strategies were presented in the paper and discussed according to the CFD and network model results. Although the current network model has proven to be adequate for preliminary analysis of the control strategies, a more detailed model could be suited for more detailed analyses.

The next step is to conduct further field tests for supplementary knowledge of dynamic thermal behaviour of the system such as the effect of gravity, fluid property variations with temperature, pressure and water content, ice formation and its possibility to block airflow paths within the NHEA's porous zone. Explicitly considering these parameters in CFD and network models will allow for more detailed analysis of the potential engineered modifications to the system to enhance the NHEA.

\section{Acknowledgement}

This work has been supported by the Ultra-Deep Mining Network (UDMN) at the Centre for Excellence in Mining Innovation (CEMI). The authors acknowledge the support of Vale, Sudbury, Ontario Division, especially the input from Paul Aho, ventilation specialist, Brian Keen, ventilation supervisor, and Simon Nickson, underground mining specialist. Contributing MIRARCO interns include Dylan Caverson and Thayna de Almeida.

\section{References}

ANSYS, Inc. 2017, ANSYS 17.1, ANSYS, Inc., Canonsburg, viewed 29 May 2017, http://www.ansys.com/

Environment and Climate Change Canada 2017, Historical Data - Climate, Government of Canada, viewed 2 March 2017, http://climate.weather.gc.ca/historical_data/search_historic_data_e.html

McPherson, MJ 1993, Subsurface Ventilation and Environmental Engineering, Chapman and Hall, London.

Ramsden, R, Allen, C, Millar, D \& Guse, T 2014, 'The use of natural cooling to delay and reduce refrigeration requirements', in F von Glehn \& M Biffi (eds), Proceedings of the Tenth International Mine Ventilation Congress, The Mine Ventilation Society of South Africa, Sun City, pp. 27-32.

Schafrik, S 2014, The Use of Packed Sphere Modelling for Airflow and Heat Exchange Analysis in Broken or Fragmented Rock, $\mathrm{PhD}$ thesis, Laurentian University, Sudbury.

The MathWorks, Inc. 2017, MATLAB, The MathWorks, Inc., Natick, viewed 29 May 2017, https://www.mathworks.com/ products/matlab.html 
